\title{
An Empirical Examination of Peer vs. Expert Advice in Online Forums
}

\author{
Kelly J. Fadel \\ Utah State University \\ kelly.fadel@usu.edu
}

\author{
Matthew L. Jensen \\ University of Oklahoma \\ mjensen@ou.edu
}

\author{
Michael J. Matthews \\ University of Oklahoma \\ michael.j.matthews- \\ 1 @.ou.edu
}

\author{
Thomas O. Meservy \\ Brigham Young University \\ tmeservy@byu.edu
}

\begin{abstract}
Online discussion forums sponsored by electronic networks of practice offer a popular platform for a variety of participants to share their knowledge and provide feedback, including subject matter experts and a larger body of "peer" forum users with no particular expertise. Although prior research suggests that both expert and peer forum contributions can influence information seekers, current literature offers little guidance that explains how and when one is more influential than the other. This paper reports the results of two studies, a structured survey and a choice-based conjoint study, conducted to empirically validate a previously derived conceptual framework of 16 situational characteristics related to peer and expert advice seeking on forums. The results of our work offer theoretical and practical guidance for ongoing work in this area.
\end{abstract}

\section{Introduction}

Electronic Networks of Practice (ENPs), are "computer-mediated social spaces where individuals working on similar problems self-organize to help each other and share knowledge, advice, and perspectives about their occupational practice or common interests" [1:254]. One of the primary communication tools used by ENP participants is the online discussion forum, where users can go to post questions to other network participants, answer questions posted by others, or review communication exchanges between prior information seekers and responders. Recent data show that online forums are a widespread and popular information source for those who seek knowledge online, with $88 \%$ of social media users indicating that they belong to online discussion communities, and $72 \%$ reporting that they find forums to be a more reliable and trustworthy information source than traditional social media platforms such as Twitter and Facebook [2]. Despite their growing popularity, however, relatively little is understood about how information found on online forums is filtered, evaluated, and adopted by those who use them as an information source.

One of the primary characteristics of most online forums is that they feature contributions from different types of participants. At a broad level, some contributors can be classified as subject matter experts: forum users with credentials or badges that identify them as possessing verified expertise on the topic in question. For example, select users of the popular programming forum StackOverflow are designated as topical experts using special tags and icons associated with their user profile. On the other hand, the majority of forum users are better described as peers, those who have an interest in or opinion about the topic but who lack any particular expertise. Many participants on Cookingbites.com, for example, are designated as "regular users" who have interest in, but no particular expertise about, culinary topics. Forums such as these typically allow both expert and peer users to post their own contributions (e.g., provide an answer to another participant's question) or to render feedback the contributions of others (e.g., endorse/critique others answers via acceptance check marks, up/down votes, star ratings, etc.).

Nascent research on ENP forums suggests that both expert- and peer-originating content can influence forum information seekers but has thus far offered inconclusive results about the relative effect of peer and expert forum contributions in different contexts [3]. Advancing scientific knowledge on this topic is important for at least two reasons. First, as forums continue to grow in number and popularity encompassing topics ranging from private hobbies to public health, political, and social justice issues - they exert an increasing influence on public and private choice. Unpacking the influence mechanisms behind this choice is a critical step to understanding both the flow and consequences of forum-based information gathering and the decisions that result from it (e.g., should I receive a COVID-19 vaccination?). Second, online forums provide a unique environment where expert input (e.g., a post authored or endorsed by a subject matter expert) is often juxtaposed with the input of the wider masses of "peer" users (e.g., community 
up/down votes or star ratings attached to a post). Forum users must therefore decide how they will weigh these sources in their information gathering process. The salience of this decision has come into sharp relief in recent years, as expert opinions have often been expressly discounted or dismissed in favor of the more populist "wisdom of the crowds" [4].

In this paper, we report the results of two mixedmethod studies designed to examine when and why people prefer the opinions of experts vs. peers in contexts typical of those discussed on online forums. First, we analyze data from a structured survey designed to quantify the relationship between peer/expert adviceseeking and 16 situational characteristics derived from previous research [5]. We then conduct two choicebased conjoint analysis studies in which participants are asked to choose between hypothetical forum answers with various levels of expert or peer endorsement. For theory, our work establishes and empirically validates an organizing conceptual framework for an ongoing research program designed to explain the circumstances under which different sources of information are more influential when seeking information on online forums, an important building block toward a larger theory that predicts and explains how forum information sources are used in various decision-making contexts. For practice, our results offer actionable guidance for forum designers and moderators to recruit and/or drive contributions of the most effective information sources depending on the topical nature of the forum itself or the queries posted to it.

\section{Background}

The question of when and why people prefer information from experts vs. peers is both fundamental and ongoing in several research domains $[6,7,8,9,10]$. Because expertise stems from a sophisticated understanding of a topic, one might expect information seekers to exhibit a reliably strong preference for expert opinions [11, e.g., 12]. However, prior research has demonstrated a divergence in opinion regarding expertise in answer sources $[13,10]$. For example, some prefer referencing medical doctors who can speak in depth regarding side-effects of medication, but others prefer individuals currently taking the medication who can discuss the day-to-day experience of treatment [14]. Some scholars have found greater bias stemming from crowdsourcing [8], while others have found little difference between peer evaluation and expert review [7]. Thus, the process and dimensions by which individuals evaluate sources to determine who can provide the needed answer are unclear [3]. For instance, the evaluation might be based on an estimation of specialized, technical knowledge or successful (or perhaps unsuccessful) personal experience. Finally, even the role of expertise in online forums has recently been fundamentally questioned. Some scholars observe a diminishing role for expertise as online information seekers attempt to learn about topics rather than fully and deeply understand them [15]. Still others claim that legitimate expertise is no longer relevant as large numbers of lay-people regularly surpass expert performance (i.e., wisdom of crowds) [4].

Studies across various domains of judgment and decision-making suggest that situational factors could drive preference for peer vs. expert advice. For example, research suggests that people seem to prefer the opinion of experts in situations that are highly complex and require advanced levels of cognitive processing [16, 14, 17] or that possess a high degree of risk and uncertainty $[18,19]$. Conversely, experts' opinions are sometimes disregarded based on potential ulterior motives or bias in their response [8], or when their lack of rapport or connection with the information seeker casts doubt on the applicability of their recommendations. Similarly, some studies suggest that the opinion of peers may be preferred in "experiential" situations that are perceived subjectively or situations that are based on personal preference or taste $[20,18]$. However, peer opinions can also be discounted in other scenarios when their feedback is perceived as anecdotal, uninformed, illintentioned, or the function of herding [21]. Indeed, some scholars have cautioned against the "madness of crowds" [21], but others have highlighted the "wisdom of crowds" [22].

To build theoretical understanding of what drives the preference for peer or expert advice on forums, Meservy et al. [5] conducted an open-ended, qualitative survey in which participants were asked to describe characteristics of situations that would lead them to favor peer or expert advice on forums. Their analysis revealed 10 situational characteristics that favored expert advice, and six that favored peer advice. Each characteristic was further classified as focusing on the person providing the information, the nature of the problem to be solved, or the nature of the proposed solution to the problem. Expert advice was preferred when the problem involved high stakes, the solution was complex, expensive, or unverifiable, and the person providing the advice required specialized knowledge or deep experience. In contrast, peer advice was preferred when the problem was low-stakes, commonly experienced, or subjective; when the solution was simple, inexpensive, or verifiable; and in situations when a variety of opinions was desired, or when the person providing the advice was preferred to have personal experience with the situation, be unbiased, or possess traits that were relatable to the advice seeker. (See [5] for more detailed definitions of these constructs.) 
Although the work presented in Meservy et al. [5] provides useful theoretical groundwork by identifying what situational characteristics might guide information seekers to peers or experts, the relationships between these characteristics and peer/expert advice preferences were not empirically tested. This leaves open the important theoretical question of which situational characteristics/categories are most salient for predicting preferences between peer vs. expert advice. In the following sections, we report the results of two studies designed to (a) quantify the relative effect of these characteristics across different situations, and (b) test whether situations that differ on these characteristics indeed elicit a diverging preference for peer vs. expert advice.

\section{Method \& Results}

\subsection{Study 1 Method and Data Collection}

In study 1 , we sought to empirically test the 16 characteristics from Meservy et al. [5] using data collected from a structured survey instrument. We designed a questionnaire that defined each characteristic and then prompted individuals with 20 hypothetical scenarios taken from a popular press article [23]. Scenarios comprised life situations that involved deciding or taking action, such as choosing a travel destination, selecting a product to purchase, or deciding on a college major (see Table 2 below for a full list). These scenarios were chosen as likely to exhibit variation in reliance on peer vs. expert opinions [23] and because they represented topics for which one might seek answers on an online forum. For each scenario, presented in random order, participants were instructed to indicate whether they would be more likely to seek advice from an expert (defined as a person with credentials or demonstrated expertise about the situation) or a peer (defined as a person who is similar to you and may have some personal experience with the situation) using a five-point scale ranging from "1definitely peer" to "5-definitely expert." Additionally, for each scenario, participants were asked to select at least one and up to three of the situational characteristics from Meservy et al. [5] that best explained the rationale for their peer-expert rating. Eight of these characteristics already represented complementary ends of a continuum (expensive/inexpensive, high stakes/low stakes, simple/complex, verifiable/unverifiable). For the other eight (e.g., subjective), we created a complementary endpoint (e.g., objective) to maintain balance and avoid introducing bias due to the larger number of peer characteristics. Thus, in all, participants could choose from 24 distinct characteristics when explaining what would lead them to seek expert or peer advice. See Table 1 below for a full list of these characteristics.

We followed best practices for recruiting participants from M-Turk [24]. Participants each held Master status, obtained over 100 approved hits and held a $95 \%$ approval rating. A total of 113 individuals began the study and answered at least some questions; however, three participants did not complete the study and thus were excluded from the analyzed data. This left a sample of 110 for analysis. Regarding demographics, 49 respondents $(44.5 \%)$ reported as female, and 92 respondents $(83.6 \%)$ reported at least some college education. The average reported age was $44(\mathrm{SD}=$ 9.38).

\subsection{Study 1 Analysis and Results}

We applied mixed effects regression to measure how reliance on peers versus experts related to the selected characteristic(s) for each scenario. Mixed effects regression was used because the data we collected were hierarchical, with multiple characteristics selected for each scenario and multiple scenarios rated by each participant. In addition, the dependent variable of the expert-peer rating for each scenario was ordinal in nature (measured on a scale of 1 to 5 , with 5 indicating reliance on experts). Therefore, we selected cumulative link (ordinal) mixed model analysis to capture both fixed effects of the characteristics and random (grouping) effects of participants and scenarios. We used the Cumulative Link Mixed Models (CLMM) function of the ordinal package in $\mathrm{R}[25,26]$ to estimate ordinal mixed effects regression models. We first determined the viability of our model by creating an initial baseline model with random effects only and then a model with fixed effects added. The two models were significantly different from each other $(p<.001)$, and the AIC for the full model indicated that it was a better fit over the baseline model (full model AIC 16488.79; baseline model AIC 17378.87). Table 1 shows the estimates and the odds ratios for all 24 characteristics.

The data presented in Table 1 show which characteristics are most influential when selecting peers versus experts for each scenario. Peer advice is more commonly sought when the person providing the advice requires no specialized knowledge but has personal experience and is highly relatable, and when the problem is commonly experienced and the solution is simple, among other factors. Expert advice is preferred most often when a person with specialized knowledge is desired, when the situation is high-stakes and not commonly experienced, and when the solution is complex or expensive. Of the original 16 characteristics identified in study 1 , four of the peer-related 
characteristics (high variety, low bias, low stakes, and inexpensive) and one of the expert characteristics (unverifiable) did not have a statistically significant effect on the model. Of the eight characteristics included as "artificial" complements, only three (uncommonly experienced, non-specialized knowledge, objective) were significant. Finally, all significant relationships in the model were in the anticipated direction except for verifiable, which was associated with reduced reliance on peer input.

Table 1. CLMM model of peer and expert characteristics

\begin{tabular}{|c|c|c|c|c|c|}
\hline \multirow{2}{*}{$\begin{array}{l}\text { Peer Characteristics } \\
\text { Characteristic }\end{array}$} & \multicolumn{5}{|c|}{ Expert Characteristics } \\
\hline & Estimate (SE) & $\begin{array}{l}\text { Odds } \\
\text { Ratio }^{++}\end{array}$ & Characteristic & Estimate (SE) & $\begin{array}{l}\text { Odds } \\
\text { Ratio }\end{array}$ \\
\hline Person & & & Person & & \\
\hline $\begin{array}{l}\text { Non-specialized } \\
\text { knowledge }^{\dagger}\end{array}$ & $-0.81(0.31) * *$ & 2.26 & Specialized knowledge & $1.59(0.13) * * *$ & 4.89 \\
\hline Personal experience & $-1.32(0.12) * * *$ & 3.76 & Impersonal Experience $^{\dagger}$ & $0.15(0.29)$ & 1.16 \\
\hline Shallow experience ${ }^{\dagger}$ & $-0.3(0.37)$ & 1.35 & Deep experience & $0.68(0.16) * * *$ & 1.98 \\
\hline High variety & $0.01(0.2)$ & 0.99 & Low variety ${ }^{\dagger}$ & $0.05(0.62)$ & 1.05 \\
\hline High relatability & $-1.07(0.15) * * *$ & 2.93 & Low relatability ${ }^{\dagger}$ & $-0.53(0.47)$ & 0.59 \\
\hline Low bias & $0.13(0.19)$ & 0.88 & High bias ${ }^{\dagger}$ & $0.11(0.2)$ & 1.12 \\
\hline Problem & & & Problem & & \\
\hline Low stakes & $-0.34(0.23)$ & 1.40 & High stakes & $0.91(0.16) * * *$ & 2.49 \\
\hline Commonly experienced & $-0.73(0.13) * * *$ & 2.08 & Uncommonly experienced $^{\dagger}$ & $0.99(0.42) *$ & 2.68 \\
\hline Subjective & $-0.51(0.15) * * *$ & 1.66 & Objective $^{\dagger}$ & $0.56(0.16) * * *$ & 1.74 \\
\hline Solution & & & Solution & & \\
\hline Simple & $-0.61(0.17) * * *$ & 1.84 & Complex & $0.8(0.13) * * *$ & 2.23 \\
\hline Inexpensive & $-0.46(0.27)^{\bullet}$ & 1.58 & Expensive & $0.78(0.16) * * *$ & 2.17 \\
\hline Verifiable & $0.43(0.15) * *$ & 0.65 & Unverifiable & $0.04(0.3)$ & 1.04 \\
\hline
\end{tabular}

$\cdot p<.10 ; * p<.05 ; * * p<.01 ; * * * p<.001$

++ Since peer was opposite expert on the response variable scale, the signs are reversed for peer odds ratios for ease of interpretation. Therefore, higher peer odds ratios indicate higher likelihood of choosing a peer source.

$\dagger$ Not explicitly identified Meservy et al. [5] but included as a complement to another characteristic

The odds ratios shown in Table 1 provide a measure of the effect size of each characteristic on the peerexpert rating. Obtained by exponentiating the fixedeffects coefficients, these ratios quantify the odds of a one-point increase/decrease in the peer or expert rating based on the presence of the characteristic. For example, when a scenario is labeled as requiring specialized knowledge, the odds of a one-point shift toward reliance on experts increases by a factor of $e^{1.59}=4.89$. Because the dependent variable is measured on an ordinal scale ranging from 1-Definitely Peer to 5-Definitely Expert, a negative coefficient in the model indicates that the characteristic is more associated with peers. To improve interpretability, we calculated all odds ratios for peer characteristics using the negated value of the estimate. Thus, for example, a scenario marked as requiring personal experience decreases odds of relying on an expert by a factor of $e^{-1.32}=0.27$ and increases odds of relying on peers by a factor of $e^{1.32}=3.76$.

In addition to quantifying the effect of each characteristic on the peer-expert rating, we explored whether certain scenario subgroups showed common patterns of characteristics and whether these groups occupied statistically different positions from each other on the peer-expert scale. To do this, we tabulated the total number of times each characteristic was associated with each scenario and conducted a k-means cluster analysis on the 20 scenarios using the characteristic frequency counts as clustering variables. Cluster analysis was performed in $\mathrm{R}$ using the fviz_nbclust method of the factoextra v1.0.7 package [27] and the kmeans method of the cluster v2.1.0 package [28]. The elbow method [29] suggested an optimal solution of three clusters. Table 2 shows how the scenarios were 
clustered and reports the mean value of the peer-expert rating for each scenario and each cluster.

As illustrated in Table 2, scenarios fell into three distinct clusters that cleanly break across the average peer versus expert ratings. The first cluster comprises peer-oriented scenarios that require personal experience and are commonly experienced, subjective, and simple. The third cluster contains expert-oriented scenarios that require specialized knowledge and are expensive, complex, and high-stakes. Scenarios in in the second cluster fall somewhere in the middle where individuals cite characteristics that are frequently attributed to either experts or peers, including specialized knowledge for complex situations but that may also benefit from personal experience to commonly experienced scenarios. We, therefore, term scenarios in this cluster as mixed-source-oriented scenarios.

Table 2. Scenario clusters

\begin{tabular}{|c|c|c|}
\hline Scenario & $\begin{array}{l}\text { Peer vs. } \\
\text { Expert } \\
\text { Rating }\end{array}$ & Cluster \\
\hline $\begin{array}{l}\text { Deciding to try a new } \\
\text { restaurant }\end{array}$ & 1.65 & \multirow{6}{*}{$\begin{array}{c}\begin{array}{c}\text { Peer- } \\
\text { oriented }\end{array} \\
\text { (avg peer- } \\
\text { expert } \\
\text { rating: } \\
2.0 \text { ) }\end{array}$} \\
\hline $\begin{array}{l}\text { Determining whether a } \\
\text { movie is worth seeing }\end{array}$ & 1.76 & \\
\hline $\begin{array}{l}\text { Determining my romantic } \\
\text { capability with someone }\end{array}$ & 2.04 & \\
\hline $\begin{array}{l}\text { Seeking relationship } \\
\text { advice }\end{array}$ & 2.06 & \\
\hline $\begin{array}{l}\text { Deciding on a travel } \\
\text { destination }\end{array}$ & 2.14 & \\
\hline $\begin{array}{l}\text { Determining whether to } \\
\text { purchase a certain product }\end{array}$ & 2.38 & \\
\hline $\begin{array}{l}\text { Determining whether to } \\
\text { do business with a certain } \\
\text { company }\end{array}$ & 2.73 & \multirow{9}{*}{$\begin{array}{l}\text { Mixed- } \\
\text { source- } \\
\text { oriented } \\
\text { (avg peer- } \\
\text { expert } \\
\text { rating: } \\
3.1 \text { ) }\end{array}$} \\
\hline $\begin{array}{l}\text { Determining whether to } \\
\text { purchase a new personal } \\
\text { computer or mobile phone }\end{array}$ & 2.82 & \\
\hline $\begin{array}{l}\text { Trying to make sense of a } \\
\text { current news event }\end{array}$ & 2.84 & \\
\hline Deciding who to vote for & 2.85 & \\
\hline $\begin{array}{l}\text { Selecting my fantasy } \\
\text { football lineup }\end{array}$ & 2.98 & \\
\hline Selecting a college major & 3.40 & \\
\hline Deciding on a career & 3.41 & \\
\hline $\begin{array}{l}\text { Choosing among car } \\
\text { insurance providers }\end{array}$ & 3.42 & \\
\hline $\begin{array}{l}\text { Seeking advice on a } \\
\text { diet/exercise plan }\end{array}$ & 3.53 & \\
\hline $\begin{array}{l}\text { Deciding whether to lease } \\
\text { or purchase a vehicle }\end{array}$ & 3.61 & $\begin{array}{l}\text { Expert- } \\
\text { Oriented }\end{array}$ \\
\hline
\end{tabular}

\begin{tabular}{|c|c|c|}
\hline $\begin{array}{l}\text { Deciding which credit } \\
\text { card is best for me }\end{array}$ & 3.95 & \multirow{4}{*}{$\begin{array}{l}\text { (avg peer- } \\
\text { expert } \\
\text { rating: } \\
4.1 \text { ) }\end{array}$} \\
\hline $\begin{array}{l}\text { Seeking advice on } \\
\text { purchase a home }\end{array}$ & 4.23 & \\
\hline Seeking financial advice & 4.34 & \\
\hline $\begin{array}{l}\text { Seeking advice on how to } \\
\text { get a good loan }\end{array}$ & 4.37 & \\
\hline
\end{tabular}

We further validated the scenario cluster segmentation by statistically comparing the mean values of the scenarios in each cluster on the peer-expert scale. A one-way analysis of variance revealed that there were significant differences between clusters $(\mathrm{F}(2,17)=$ $27.11, \mathrm{p}<.001)$ on this scale. A Tukey post hoc test to correct for multiple comparisons revealed significant differences between all three clusters: the average rating for scenarios in the expert-oriented cluster was significantly higher (indicating a greater reliance on experts) than that of the mixed-source-cluster $(p<0.001)$ which, in turn, was significantly higher than that of the peer-oriented cluster $(\mathrm{p}<0.05)$. These tests further confirm that the identified situational characteristics offer explanatory power in distinguishing between peer and expert advice preference.

\subsection{Study 2 Method}

To further validate the conceptual framework, we devised a between-subjects, discrete choice conjoint analysis study in which participants chose between hypothetical forum solutions based on cues that indicate an endorsement from peers or experts. Conjoint analysis is an experimental technique "based upon rigorous research on information processing in judgment and decision making" [30:356] that "requires respondents to make a series of judgments, assessments or preference choices, based on profiles from which their 'captured' decision processes can be decomposed into its underlying structure" [31:207]. While there are many conjoint methodologies (e.g., adaptive conjoint, partialprofile, menu-based, full-profile), we chose a choicebased conjoint $(\mathrm{CBC})$ approach for this study. $\mathrm{CBC}$ most closely mimics a real-world experience of making choices given various options and is uniquely designed to identify and then rank the criteria that individuals use in their decision-making [32]. In a CBC design, the participant is presented with a series of choice sets, each of which contains alternatives (e.g., forum solutions) that consist of a set of attributes (e.g., expert, peer ratings) with different levels (e.g., positive, negative, missing). The participant selects one alternative from each choice set based on her preference for the combination of attribute levels in that alternative. Through repeated alternative selections, conjoint 
analysis isolates the importance of each attribute and its utility relative to other attributes in the selection decision. This importance is measured by attribute partworth utilities, which quantify the overall relative importance of an attribute in the decision-making process, and level partworth utilities, which decompose attribute partworth utilities to show the relative influence of each attribute level. The calculation of these partworth utilities is derived from a hierarchical logit model that estimates regression parameters for each attribute level on the final selection decision. These parameters can also be used to derive odds ratios (ORs) that measure the effect size of the presence or absence of an attribute level on the selection decision.

\subsection{Study 2 Data Collection}

We designed two independent $\mathrm{CBC}$ data collection instruments, each featuring one of the scenarios from study 1 . The central question examined by these studies was whether choice patterns between forum solutions endorsed by peers vs. those endorsed by experts would differ based on the scenario in question. To answer this question, we selected one scenario from the peeroriented cluster and one scenario from the expertoriented cluster to serve as the context for each $\mathrm{CBC}$ analysis, as these clusters exhibited the most divergent peer/expert preferences. We used the deciding to try a new restaurant scenario from cluster 1, as it was widely applicable and exhibited the strongest preference for peer input in study 1. Participants were told to imagine that they were traveling to a new city and searching on a restaurant forum for a good place to have dinner. From cluster 3, we chose the seeking financial advice scenario, as it demonstrated a strong orientation toward expert advice and was more broadly applicable than seeking advice on how to get a good loan, which had the highest (though not statistically different) expert preference score. Participants were told to imagine that they were searching an investment forum for advice about how to invest their retirement savings.

A separate but parallel $\mathrm{CBC}$ instrument was designed for each scenario. The instrument presented participants with a series of choice sets, each of which consisted of three hypothetical forum posts (or "answers") pertaining to the scenario. To isolate the effects of peer/expert endorsements, we did not display the content of the answers. Instead, each answer was represented by a set of three cues typical of those found on actual online forums. One cue represented feedback on the answer from a domain expert. The other two cues represented two different sources of peer feedback about the answer: (a) the original poster (OP; the person who posted the question for which the answer was written) and (b) the general community of forum users. To avoid confounding effects due to inconsistent formats, we presented all cues with a consistent ternary graphic that indicated one of three levels: endorsed (green check mark), rejected (red x), or not evaluated (blank) by each source.

Figure 1 depicts a sample choice set in the $\mathrm{CBC}$ instrument, which consists of three alternative forum answers each characterized by different levels of the cues described above. For each choice set, individuals choose a single forum answer that represents the one they would be most likely to adopt among the three alternatives. (Optionally, participants can choose "None of the Above" option if none of the presented alternatives are acceptable, consistent with the traditional design [32]). As users make repeated selections across multiple choice sets (typically 10-12), the $\mathrm{CBC}$ algorithm isolates the relative importance of both the attributes and the levels of each attribute, as reflected by the computed attribute and level partworth utilities. To optimize this process, the CBC software dynamically determines the number of choice sets and the attribute levels shown for each alternative based on participant selections.

After displaying the CBC choice sets, the instrument presented participants with a series of post questions regarding their usage of forums, motivation to complete the experiment, and demographic variables. As with study 2, we followed best practices for recruiting participants from M-Turk [24]. Participants each had Master status, had over 100 approved hits, and had at least a 95\% approval rating. A total of 293 individuals began the survey, of which 62 did not complete the study, failed attention or time checks, or were screened out. This left a sample of 231, which exceeded the recommended sample size of 100 participants per treatment suggested by the CBC software provider. 113 participants (48.9\%) were female, reported an average age of $41.1 \quad(\mathrm{SD}=11.0)$ years, and 213 respondents $(92.2 \%)$ reported having at least some college education. On a 5-point scale (1Never; 5-All the Time), participants reported being familiar with searching online forums to find answers to problems (average $=4.358$ s.d. $=0.76$ ). They also reported being highly motivated (avg=4.88; s.d.=.36; 1 -Strongly disagree; 5-Strongly agree) to select the best solutions during the experiment. Participants were randomly assigned to either the restaurant or retirement scenario and subsequently responded to $10-12$ choice sets as demonstrated in Figure 1. 


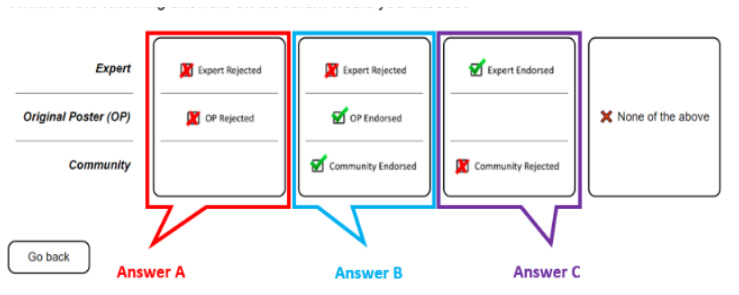

Figure 1. Study 2 stimulus material

\subsection{Restaurant CBC Results}

The CBC model generated for the restaurant scenario demonstrates that the peer and expert cues provided strong explanatory power for predicting solution adoption (McFadden's pseudo- $\mathrm{R}^{2}=80 \%$ ). To examine the effect of situational characteristics on the preferred information source, we refer to the attribute and level partworth utilities derived from this model. We anticipated that peer cues (OP and community members) would be more influential than the expert cue. The attribute partworth utilities from our analysis demonstrate that the community cue exerted the strongest overall effect on the adoption decision $(37.4 \%$; 95\% CI: $36.10-38.78)$, followed by the expert (35\%; 95\% CI: $33.74-36.27)$ and OP (27.6\%; 95\%CI: 27.56 - 28.37) cues. The 95\% confidence intervals of these utilities suggest that the effects of community and expert cues were significantly greater than that of the OP cue. However, the overlapping attribute partworth confidence intervals for community and expert cues suggest the possibility that these two characteristics did not differ in their effect. To explore this further, we examine the corresponding mlogit regression results (Table 3) to understand the effects of each attribute level (endorsed, missing, rejected). As shown in Table 3, the estimate confidence intervals for the endorsed level of expert and community overlap, and a Wald test confirms no significant difference in the corresponding regression coefficients of 1.79 and $1.88 \quad(\mathrm{~W}=1.29 ; \mathrm{p}=0.2)$. However, significant differences do exist for the rejected levels of these attributes, with rejection by the community having a significantly greater diminishing effect on solution adoption than rejection by an expert. The magnitude of these effects is further illustrated by the mlogit regression odds ratios reported in Table 3, which show the effects of each attribute level relative to the baseline (intercept-only) proportional odds of a solution being selected. Holding other variables constant, endorsement by the community $(\beta=1.88, \mathrm{p}<$ .001 ) increased the odds of solution selection by a factor of 6.58 over the baseline, while an endorsement by an expert $(\beta=1.79, p<.001)$ increased the odds of a solution selection by a similar factor of 6.0. However, rejection of a solution by the community $(\beta=-1.55, \mathrm{p}<$
$.001)$ reduced the odds of selection by $79 \%(\mathrm{OR}=0.21)$, which was significantly larger than the corresponding $67 \%(\mathrm{OR}=0.33)$ odds reduction of expert rejection $(\beta=$ $-1.11, \mathrm{p}<.001)$ and the $64 \%(\mathrm{OR}=0.36)$ odds reduction of OP rejection $(\beta=-1.01, p<.001)$. Interestingly, the effect of a missing expert cue $(\beta=-0.68, p<.001$, $\mathrm{OR}=0.50$ ) had a somewhat larger impact than the identical effects a missing OP or community cue $(\beta=$ $0.33, \mathrm{p}<.001, \mathrm{OR}=0.72$ ).

Table 3. Coefficients, standard errors, confidence intervals, and odds ratios for restaurant scenario

\begin{tabular}{|c|c|c|c|c|c|}
\hline $\begin{array}{l}\text { Attr. } \\
\text { Level }\end{array}$ & Estimate & SE & $\begin{array}{l}\text { Lower } \\
\text { bound } \\
\text { (95\% } \\
\text { CI) }\end{array}$ & $\begin{array}{l}\text { Upper } \\
\text { bound } \\
\text { (95\% } \\
\text { CI) }\end{array}$ & $\begin{array}{l}\text { Odds } \\
\text { ratio }\end{array}$ \\
\hline $\begin{array}{l}\text { Expert - } \\
\text { Endorsed }\end{array}$ & $1.79 * * *$ & 0.094 & 1.61 & 1.98 & 6.00 \\
\hline $\begin{array}{l}\text { Expert - } \\
\text { Missing }\end{array}$ & $-0.68 * * *$ & 0.090 & -0.86 & -0.51 & 0.50 \\
\hline $\begin{array}{l}\text { Expert - } \\
\text { Rejected }\end{array}$ & $-1.11 * * *$ & 0.098 & -1.30 & -0.92 & 0.33 \\
\hline $\begin{array}{l}\text { OP - } \\
\text { Endorsed }\end{array}$ & $1.34 * * *$ & 0.078 & 1.18 & 1.49 & 3.81 \\
\hline $\begin{array}{l}\text { OP - } \\
\text { Missing }\end{array}$ & $-0.33 * * *$ & 0.078 & -0.48 & -0.17 & 0.72 \\
\hline $\begin{array}{l}\text { OP - } \\
\text { Rejected }\end{array}$ & $-1.01 * * *$ & 0.095 & -1.20 & -0.82 & 0.36 \\
\hline $\begin{array}{l}\text { Community } \\
\text { - Endorsed }\end{array}$ & $1.88 * * *$ & 0.094 & 1.70 & 2.07 & 6.58 \\
\hline $\begin{array}{l}\text { Community } \\
\text { - Missing }\end{array}$ & $-0.33 * * *$ & 0.093 & -0.52 & -0.15 & 0.72 \\
\hline $\begin{array}{l}\text { Community } \\
\text { - Rejected }\end{array}$ & $-1.55 * * *$ & 0.103 & -1.75 & -1.35 & 0.21 \\
\hline
\end{tabular}

\subsection{Retirement CBC Results}

As with the restaurant scenario, the CBC model generated for the retirement scenario demonstrates that the contextual cues provided strong explanatory power for predicting solution adoption (McFadden's pseudo$\mathrm{R}^{2}=81 \%$ ). Once again, we examine the attribute and level partworth utilities derived from this model to highlight the reliance on peers versus experts for this scenario. We expected that experts would be significantly more influential than peers, and this was confirmed by the $\mathrm{CBC}$ analysis. The computed attribute partworth utilities demonstrated that expert endorsement (46.4\%; 95\% CI: 45.00 - 47.79) exerted the strongest effect on the adoption decision, followed by community endorsement $(29.1 \%$; $95 \%$ CI: $28.30-$ $29.97)$ and OP acceptance (24.5\%; 95\% CI: $23.64-$ 25.30). The partworth utility confidence intervals suggest that the overall effect of the expert cue was significantly stronger than that of the community, which, in turn, was stronger than that of the OP cue. The 
mlogit regression results in Table 4 show that expert endorsement $(\beta=2.84, p<.001)$ increased the odds of selection by a factor of 17.18 , which easily outstripped the more modest increase in odds of community $(\beta=$ $1.75, \mathrm{p}<.001, \mathrm{OR}=5.74)$ or OP $(\beta=1.49, \mathrm{p}<.001$, $\mathrm{OR}=4.45$ ) endorsement. Similarly, rejection by an expert $(\beta=-2.03, \mathrm{p}<.001, \mathrm{OR}=0.13)$ had a more deleterious effect on answer selection than rejection by the community $(\beta=-1.23, \mathrm{p}<.001, \mathrm{OR}=0.29)$ or by the OP $(\beta=-1.00, p<.001, \mathrm{OR}=0.37)$. The difference was not as pronounced at the missing level, where an absent expert cue $(\beta=-0.81, \mathrm{p}<.001, \mathrm{OR}=0.44)$ was only marginally more impactful than an absent community $(\beta$ $=-0.51, \mathrm{p}<.001, \mathrm{OR}=0.60)$ or OP $(\beta=-0.49, \mathrm{p}<.001$, $\mathrm{OR}=0.61)$ cue. A Wald test showed significant differences when the expert cue was missing compared to when the community $(\mathrm{W}=2.83, \mathrm{p}<.01)$ or the OP $(\mathrm{W}=2.59, \mathrm{p}=.01)$ were missing.

Table 4. Coefficients, standard errors, confidence intervals, and odds ratios for the retirement scenario

\begin{tabular}{|c|c|c|c|c|c|}
\hline Attr. Level & Estimate & SE & $\begin{array}{l}\text { Lower } \\
\text { bound } \\
(95 \% \\
\text { CI) }\end{array}$ & $\begin{array}{l}\text { Upper } \\
\text { bound } \\
\text { (95\% } \\
\text { CI) }\end{array}$ & $\begin{array}{l}\text { Odds } \\
\text { ratio }\end{array}$ \\
\hline $\begin{array}{l}\text { Expert - } \\
\text { Endorsed }\end{array}$ & $2.84 * * *$ & 0.141 & 2.57 & 3.12 & 17.18 \\
\hline $\begin{array}{l}\text { Expert - } \\
\text { Missing }\end{array}$ & $-0.81 * * *$ & 0.101 & -1.01 & -0.61 & 0.44 \\
\hline $\begin{array}{l}\text { Expert - } \\
\text { Rejected }\end{array}$ & $-2.03 * * *$ & 0.138 & -2.30 & -1.76 & 0.13 \\
\hline $\begin{array}{l}\text { OP - } \\
\text { Endorsed }\end{array}$ & $1.49 * * *$ & 0.102 & 1.29 & 1.69 & 4.45 \\
\hline $\begin{array}{l}\text { OP - } \\
\text { Missing }\end{array}$ & $-0.49 * * *$ & 0.083 & -0.65 & -0.33 & 0.61 \\
\hline $\begin{array}{l}\mathrm{OP}- \\
\text { Rejected }\end{array}$ & $-1.00 * * *$ & 0.099 & -1.20 & -0.81 & 0.37 \\
\hline $\begin{array}{l}\text { Community } \\
\text { - Endorsed }\end{array}$ & $1.75 * * *$ & 0.108 & 1.54 & 1.96 & 5.74 \\
\hline $\begin{array}{l}\text { Community } \\
\text { - Missing }\end{array}$ & $-0.51 * * *$ & 0.106 & -0.72 & -0.31 & 0.60 \\
\hline $\begin{array}{l}\text { Community } \\
\text { - Rejected }\end{array}$ & $-1.23 * * *$ & 0.098 & -1.43 & -1.04 & 0.29 \\
\hline
\end{tabular}

\section{Discussion}

As online forums associated with ENPs continue to expand in popularity, understanding how information seekers employ them to acquire information is of high practical and theoretical import. This research examined the conditions under which people are more likely to rely on the opinions of experts vs. the opinions of peers, two common subgroups of the general population of forum users. Starting from a conceptual framework of situational characteristics developed in prior research [5], we adopted a mixed-method investigation in this paper to (a) validate the core characteristics and gauge their relative theoretical importance; and (b) demonstrate how scenarios shown to differ on these characteristics vary in choosing experts vs. peers in a hypothetical forum choice task. The results of our work offer several important theoretical and practical implications and several directions for ongoing research.

The results of study 1 provide empirical validation of the characteristics identified in previous research [5]. All peer-related characteristics had a significant effect on the propensity to seek peer advice except for low stakes, inexpensive, low bias, and high variety. (Shallow experience, an endpoint we introduced to complement deep experience for experts, was also not significant.) On the expert side, all anticipated characteristics had a positive effect on expert advice seeking except for unverifiable (and high bias, low relatability, impersonal experience, and low variety, which were introduced as complementary endpoints). Cluster analysis of each of the scenarios by their characteristic ratings revealed three distinct scenario groups that orient heavily toward expert advice, orient heavily toward peer advice, or favor a mix of both. Consistent with the results of our mixed-effects ordinal regression model, personal experience was the predominant factor characterizing peer-oriented scenarios in the peer-oriented cluster, and specialized knowledge featured most prominently in the expert-oriented cluster.

One implication of these results for theory concerns the focal groupings of person, problem, and solution. Our results suggest that information seekers are primarily driven by considerations of the person providing the information; in study 1, person characteristics exerted the strongest influence on the choice between seeking input from a peer vs. from an expert in the ordinal regression model. The single most frequently mentioned person factor for peers, increasing odds of seeking peer advice by 3.76, was personal experience, suggesting that peer input is most valued in experiential situations. For experts, the most important factor was specialized knowledge (mentioned in 50\% of study 1 responses and increasing odds of seeking expert advice by 4.89 in study 2 ).

The results of the cluster analysis in study 1 also demonstrate that scenarios across a wide variety of domains can be usefully categorized according to characteristics that predict whether peer or expert advice will be most valued. Scholars can build on our results to test and further explore the nuances and boundary conditions of these relationships. For example, scenarios that share a characteristic profile similar to those in the peer-oriented (expert-oriented) cluster can be expected to favor peer (expert) input, whereas situations similar to those in the mixed-source cluster 
may require further theoretical exploration. It could be, for instance, that additional characteristics beyond those explored here could help to further discriminate source preferences for these scenarios. On the other hand, these "middle ground" scenarios-which are relatively complex and objective, and combine requirements for specialized knowledge with first-hand experience and relatability - could be those where theory might predict that one seeks both peer and expert input. This possibility is corroborated by findings from other scholars who noticed that, for some problems or questions (e.g., concerning medical treatment), input from peers and experts was sought and adopted [e.g., 33]. Learning how information search occurs in forums with these problems and answers is an important next research step, especially in cases where recommendations from experts and peers appear to be contradictory.

The results of study 2 offer confirmatory evidence that scenarios differentiated by attributes from study 1 exhibit unique patterns in the degree to which forum users rely on peer and expert opinions when selecting information on an online forum. For the peer (restaurant) scenario, although we did not detect a significant difference in the community and expert endorsement, rejection by the community had a significantly larger diminishing effect on answer selection. Moreover, both the input of community members and that of an expert seemed to outweigh that of a single peer, the OP. For the expert (retirement) scenario, the results we observed were consistent with expectations: Both endorsement and rejection by an expert had a significantly greater effect on the selection decision than did endorsement or rejection by the community or by the OP. Counter to some predictions of the demise of online expertise [15], our findings suggest a promising outlook for forums that incorporate both expert and peer information, depending on the context. The results of study 2 demonstrated that expert/peer endorsement had a uniformly positive effect on forum solution adoption, while expert/peer rejection had a uniformly negative effect. However, the relative magnitude of these effects was not uniform but varied according to the scenario in question. The increased weight of expert endorsement for the retirement scenario over the restaurant scenario suggests that expertise is clearly valued in scenarios that are highstakes and involve specialized knowledge. However, even in more common, low-stakes scenarios such as choosing a restaurant, the effect of an expert opinion exerts a diminished but non-negligible effect. Interestingly, although endorsement by an expert and the community exerted a similar influence on answer selection in the restaurant scenario, rejection by the community in the restaurant scenario was more impactful than rejection by an expert. This observation suggests the possibility of judgment asymmetries in the way that peer and expert inputs are used during information search. For example, when filtering out alternatives under consideration before adopting a single solution, individuals may rely disproportionately on collective peer opinions. Our findings suggest that judgment asymmetries may also be at work when individuals decide whether they will seek information from peers or experts.

For practice, our work underscores the value of understanding preference for experts or peers for different types of forum topics. This insight can guide governance, recruiting, and advertising efforts for forum operators or sponsors to ensure they assemble the right network composition for successful question-andanswer exchanges. Second, the strong influence of person characteristics we observed suggests that forum operators could better support users by implementing cues that focus specifically on the context-relevant dimensions of the people who post solutions. Such cues are already commonly featured on forums and include contributor ratings by information seekers and the number of contributions to the forum. However, these cues could be customized according to the forum topic to assist information seekers as they evaluate candidate solutions.

As with any research, the findings of our studies are subject to limitations that should be considered. First, to minimize fatigue, participants in study 1 were asked to select up to three situational characteristics that best accounted for their own peer/expert preferences for each scenario. This design, while purposeful, assumes that participants can faithfully report the underlying rationale(s) that would guide their preference. Future work can verify our results using alternate designs that, for example, ask participants to rate each scenario on every characteristic independently. For study 2, an important limitation is that we asked participants to select hypothetical solutions based only on contextual cues indicating peer, expert, or OP endorsement. Although this was done intentionally to isolate the effects of these cues and minimize confounding effects, it represents an abstraction of an actual forum choice task where the content of the solution itself could also be considered. Future work can examine whether the preference patterns we observed might be tempered or magnified by inclusion of solution content.

\section{References}

[1] Wasko, M.M.L., R. Teigland, and S. Faraj, "The provision of online public goods: Examining social structure in an electronic network of practice", Decision Support Systems 47(3), 2009, pp. 254-265. 
[2] Wong, W., "Study Shows Americans Prefer Online Forums Over Mainstream Social Media - Business 2 Community", 2019. https://www.business2community.com/socialmedia/study-shows-americans-prefer-online-forumsover-mainstream-social-media-02167545

[3] Jensen, M., M. Matthews, T. Meservy, and K. Fadel, "Expert vs. Peer: The Role of Situational Characteristics in Electronic Networks of Practice", Proceedings of the 54th Hawaii International Conference on System Sciences, (2021), 296-305.

[4] Sunstein, C.R., Infotopia: How Many Minds Produce Knowledge, Oxford University Press, 2006.

[5] Meservy, T., K.J. Fadel, M. Jensen, and M. Matthews, "Searching for Expert or Peer Advice in Online Forums", Proceedings of the 2021 Americas Conference on Information Systems, (2021), 1-10.

[6] Flanagin, A.J., and M.J. Metzger, "Trusting expert versus user-generated ratings online: The role of information volume, valence, and consumer characteristics", Computers in Human Behavior 29(4), 2013, pp. 16261634.

[7] Mollick, E., and R. Nanda, "Wisdom or madness? Comparing crowds with expert evaluation in funding the arts", Management Science 62(6), 2016, pp. 1533-1553.

[8] Greenstein, S., and F. Zhu, "Do experts or crowd-based models produce more bias? Evidence from encyclopedia britannica and wikipedia", MIS Quarterly 42(3), 2018, pp. 945-958.

[9] Kim, K., and S. Viswanathan, "The experts in the crowd: The role of experienced investors in a crowdfunding market", MIS Quarterly 43(2), 2019, pp. 347-372.

[10] Meservy, T.O., K.J. Fadel, C.B. Kirwan, and R.D. Meservy, "An fMRI exploration of information processing in electronic networks of practice", MIS Quarterly 43(3), 2019, pp. 851-872.

[11] Chaiken, S., and D. Maheswaran, "Heuristic Processing Can Bias Systematic Processing: Effects of Source Credibility, Argument Ambiguity, and Task Importance on Attitude Judgment", Journal of Personality and Social Psychology 66(3), 1994, pp. 460-473.

[12] Battiston, P., R. Kashyap, and V. Rotondi, "Reliance on scientists and experts during an epidemic: Evidence from the COVID-19 outbreak in Italy", SSM - Population Health 13, 2021.

[13] Hwang, E.H., P.V. Singh, and L. Argote, "Jack of all, master of some: Information network and innovation in crowdsourcing communities", Information Systems Research 30(2), 2019, pp. 389-410.

[14] Vennik, F.D., S.A. Adams, M.J. Faber, and K. Putters, "Expert and experiential knowledge in the same place: Patients' experiences with online communities connecting patients and health professionals", Patient Education and Counseling 95(2), 2014, pp. 265-270.

[15] Nicolos, T., The death of expertise: The campaign against established knowledge and why it matters, Oxford University Press, 2017.

[16] Gilens, M., and N. Murakawa, "Elite Cues and Political Decision-Making", In M.X. Delli Carpini, L. Huddy and R.Y. Shapiro, eds., Political Decision-Making, Deliberation and Participation. Emerald Publishing
Limited, 2002, 15-49.

[17] Kranzbühler, A.-M., M.H.P. Kleijnen, P.W.J. Verlegh, and M. Teerling, "The Differential Effects of Peer and Expert Ratings on Choice", Marketing Science Institute Working Paper Series(15-117), 2015, pp. 1-34.

[18] Keh, H.T., and J. Sun, "The Differential Effects of Online Peer Review and Expert Review on Service Evaluations: The Roles of Confidence and Information Convergence", Journal of Service Research 21(4), 2006, pp. 474-489.

[19] Racherla, P., and W. Friske, "Perceived 'usefulness' of online consumer reviews: An exploratory investigation across three services categories", Electronic Commerce Research and Applications 11(6), 2012, pp. 548-559.

[20] Smith, D., S. Menon, and K. Sivakumar, "Online peer and editorial recommendations, trust, and choice in virtual markets", Journal of Interactive Marketing 19(3), 2005, pp. 15-37.

[21] Mackay, C., Extraordinary popular delusions and the madness of crowds., Digireads.com Publishing, 2015.

[22] Budescu, D. V., and E. Chen, "Identifying expertise to extract the wisdom of crowds", Management Science 61(2), 2015, pp. 267-280.

[23] Jordan Grimmer, "Experts vs. Friends: The Definitive Guide to Who Influences Us and Why", Medium, 2016. https://medium.com/bestcompany/experts-vs-friendsthe-definitive-guide-to-who-influences-us-and-why$6 \mathrm{a} 0 \mathrm{aa} 609 \mathrm{c} 8 \mathrm{c} 0$

[24] Aguinis, H., I. Villamor, and R.S. Ramani, "MTurk Research: Review and Recommendations", Journal of Management 47(4), 2021, pp. 823-837.

[25] Christensen, R.H.B., "Ordinal: Regression Models for Ordinal Data", $2015 . \quad$ http://www.cran.rproject.org/package $=$ ordinal/

[26] Team, R.C., "R: A language and environment for statistical computing", 2017. https://www.r-project.org/

[27] Kassambara, A., and F. Mundt, "factoextra: Extract and Visualize the Results of multivariate data analyzes", $R$ package version 1.0.7, 2020. https://cran.rproject.org/package $=$ factoextra

[28] Maechler, M., P. Rousseeuw, A. Struyf, M. Hubert, and K. Hornik, "Cluster: Cluster Analysis Basics and Extensions.", R package version 2.1.0, 2019.

[29] Kodinariya, T.M., and P.R. Makwana, "Review on determining number of Cluster in K-Means Clustering", International Journal of Advance Research in Computer Science and Management Studies 1(6), 2013, pp. 90-95.

[30] Brønn, P.S., and E.L. Olson, "Mapping the Strategic Thinking of Public Relations Managers in a Crisis Situation: An Illustrative Example Using Conjoint Analysis", Public Relations Review 25(3), 1999, pp. 351368.

[31] Shepherd, D.A., and A. Zacharakis, "Conjoint analysis: A window of opportunity for entrepreneurship research", In Advances in Entrepreneurship, Firm Emergence and Growth. Emerald Group Publishing Ltd., 2018, 149-183.

[32] Orme, B., and K. Chrzan, Becoming an Expert in Conjoint Analysis: Choice Modeling for Pros, Sawtooth Software, Inc., 2017.

[33] Go, E., E.H. Jung, and M. Wu, "The effects of source cues on online news perception", Computers in Human Behavior 38, 2014, pp. 358-367. 